\title{
ERNESTO VOLKENING Y NICOLÁS GÓMEZ DÁVILA: FORMAS MARGINALES EN UN DIARIO DE LECTURA* DE 1973
}

\author{
Efrén Giraldo \\ Universidad Eafit, Medellín, Colombia \\ egiral25@eafit.edu.co \\ María Camila Cardona Aguirre \\ Universidad Eafit, Medellín, Colombia \\ mcardo27@eafit.edu.co
}

\begin{abstract}
RESUMEN/ ABSTRACT
El presente artículo busca examinar las estrategias de lectura y crítica que se hallan en los cinco cuadernos manuscritos que el ensayista renano Ernesto Volkening (1908-1982) dedicó a los Escolios a un texto implícito de Nicolás Gómez Dávila, obra inédita que leyó y comentó en 1973, en uno de los diarios de lectura más singulares de la historia literaria colombiana. Para ello, se examina la trayectoria de Volkening como crítico y se discute la teoría genológica que está implícita en su elección de la nota y el diario como medios de "responder" a los Escolios. Se intenta, a partir de ello, identificar cuatro tipos de comentario en su trabajo de lectura, con el fin de reconstruir un capítulo poco conocido de la crítica literaria y las formas marginales en Colombia.
\end{abstract}

Palabras clave: Ernesto Volkening, Nicolás Gómez Dávila, literatura colombiana, diario de lectura, crítica literaria.

Este artículo se deriva de la investigación "Ernesto Volkening y Nicolás Gómez Dávila. Edición crítica de los cuadernos de notas a los Escolios a un texto implícito", realizada con el apoyo de la Dirección de Investigaciones de la Universidad Eafit, Colombia, en el año 2017 
ERnesto VolKening and Nicolás Gómez Dávila: Marginalia in a 1973 READING JournaL

This article intends to show reading and critique strategies involved in five handwritten notebooks by Rhenish essayist Ernesto Volkening (1908-1982). The notebooks, one of the most singular reading journals written in Colombian literature, were composed in 1973 and were entirely dedicated to Scholia to an Implicit Text, an unpublished book by Nicolás Gómez Dávila, which he read and commented. The article deals with Volkening's career as a critic and discusses the genologic theory involved in his choice of the note and reading journal as mediums to "respond" to the Scholia. The article intends to show four types of comments in his readings to reconstruct an unknown chapter in the history of literary criticism and marginalia in Colombia.

KEYWORDS: Ernesto Volkening, Nicolás Gómez Dávila, Colombian literature, reading journal, literary criticism.

Recepción: 06/09/2017

Aprobación: 03/04/2018

\section{INTRODUCCIÓN}

La obra crítica de Ernesto Volkening abarca más de tres décadas de trabajo y discurre sobre diversos aspectos de la literatura, el arte y la cultura. Sin embargo, las letras fueron su principal foco de atención. Dentro de esta preocupación por la literatura, consignada en varias colecciones de ensayos y en contribuciones de diverso género para publicaciones periódicas, como la revista $E c o$, de la que fue su editor entre 1971 y 1973, las obras y autores colombianos constituyeron uno de los principales objetos de atención del autor. Gabriel García Márquez, de quien acaso fue el primer crítico atento, Álvaro Cepeda Samudio, José Antonio Osorio Lizarazo, Manuel Mejía Vallejo, Óscar Collazos y Álvaro Mutis son algunos de los autores de los que se ocupó.

Cuando el Instituto Colombiano de Cultura, Colcultura, publicó en 1975 una selección de los ensayos críticos de Volkening los dividió, quizás por indicación del mismo autor, en un tomo de escritos sobre asuntos literarios colombianos y latinoamericanos, al que intitularon Ensayos I. Destellos criollos (1975), y otro sobre temas foráneos: Ensayos II. Atardecer europeo (1976). En el epílogo al primero de esos tomos, Juan Gustavo Cobo-Borda resume esta doble preocupación: "Quien vio tan bien lo nuestro, era evidente que venía de lejos. [...] Hombre de dos orillas, una que se deshace, y otra que difícilmente cobra carácter, en esa tensión está, precisamente, su mérito; y lo fecundo de su tarea" (325). Además de ocuparse de las propiedades internas de 
las obras literarias, los logros estéticos de los autores y de sus características formales, los ensayos de Volkening discuten aspectos más generales, por ejemplo, las relaciones que obras y autores tienen con cuestiones sociales, políticas y culturales, así como su inscripción en diferentes tradiciones y contextos. Si bien algunos de los ensayos críticos de Volkening comentan asuntos panorámicos, la mayoría de sus trabajos se inclinan por la reseña y el estudio detallado. En este punto, la nota precisa, el apunte oportuno y el comentario lúcido se convierten en herramientas que, como se verá, dejan de ser solo medios para convertirse después en fines y, acaso, en propuestas de nuevos géneros de escritura crítica.

En el ya citado epílogo de Cobo-Borda, leemos una buena caracterización de Volkening como crítico. La transcribimos en extenso para respaldar nuestra tesis de una crítica literaria ejercida con plena conciencia de los géneros marginales de escritura, cultivados con especial dedicación por Volkening:

Nicolás Gómez Dávila dijo, en una ocasión, que Volkening, para manifestarse, requería de un espacio muy vasto: solo allí se despliega una inteligencia que compara y ordena. El ensayo, en el caso suyo, está surcado de interpolaciones, se ramifica y bifurca, mediante una prosa sui-generis, que abarca, en cada nueva estancia, horizontes más amplios, alusiones sugestivas, referencias casi secretas. Allí conviven elegías por las viejas mansiones de Chapinero, o pensamientos acerca de la apropiación de bienes culturales de raíz ajena. Al concluir, comprendemos que todo eso era necesario. Que las múltiples facetas integran el prisma, y este nunca abandona su tema: Proust y Heine, Carpentier y los presagios, la sicología de las profundidades o la necesidad de estos pueblos, de una memoria histórica que conserve y unifique, y no de una serie de recuerdos, que desaparecen (324).

Como han mostrado algunos estudiosos de las ideas y la crítica en Colombia, luego de vivir una época dominada por la generación de críticos y escritores de Los Nuevos, con Rafael Maya a la cabeza, el panorama crítico colombiano tuvo como figuras descollantes a Hernando Téllez y, posteriormente, ya en publicaciones especializadas como la revista Eco, a autores como Hernando Valencia Goelkel y el mismo Ernesto Volkening. El historiador de la crítica literaria en Colombia David Jiménez Panesso define este nuevo momento:

Ahora se trata de revisar y comprender la función del intelectual en una sociedad dominada por técnicos, científicos y gerentes. Ya no se trata de una atmósfera asfixiante por la presión de la estrechez 
pueblerina sino, al contrario, de una sociedad que por momentos parece demasiado compleja en su estructura y amenaza con escapar a la comprensión del literato (196).

Volkening se encuentra dentro de este grupo de críticos que entienden que la complejidad contextual del fenómeno literario solo puede abordarse aproximándose a la sociología, la filosofía y la política, a través de estrategias textuales más originales. En su antología del ensayo en Colombia, Óscar Torres Duque comenta así su obra crítica:

Sus análisis literarios son de una a veces exasperante minucia, cuyos puntos claves revientan de pronto como revelaciones insospechadas. Es un explorador. Y lo era con no pocas armas teóricas, las cuales no aplicaba ingenuamente como paradigmas de interpretación, sino como instrumentos iluminadores de relaciones antes nunca previstas en obras literarias muy conocidas o en situaciones históricas eternamente comentadas (243).

Con miras al análisis de los cuadernos dedicados por Volkening a Gómez Dávila, el planteamiento de Torres Duque sirve para aventurar una posible tipología de estrategias analíticas del autor, según corresponden 1) a despliegues teóricos o marcos de comprensión, 2) a aspectos particulares inmanentes de las obras o 3) a relaciones con otras obras, autores y tradiciones. Lo anterior permitiría, junto con la revisión de diferentes trabajos sobre el ejercicio de la crítica literaria en Colombia, entender la manera en que Volkening leyó los escolios de Nicolás Gómez Dávila y articuló estrategias críticas concentradas en una suerte de poética de la escritura marginal.

En las páginas que siguen, mostraremos el papel que la escritura marginal y sus géneros tienen en la lectura que Volkening hace de los escolios de Nicolás Gómez Dávila, quien era ya, incluso en ese momento prematuro de recepción (1973), uno de los más importantes cultores de formas argumentativas breves. Para ello, abordaremos el estado de la discusión sobre los géneros marginales y su relación con las artes de lectura y las actividades de la crítica. Luego, examinaremos los rasgos de la escritura al margen en la trayectoria crítica de Volkening, para después, finalmente, considerar las diferentes estrategias que ayudarían a clasificar las entradas de diario de los cinco cuadernos. 


\section{CRÍTICA, LECTURA Y MARGINALIA}

Como se sabe, la crítica ha recurrido a una amplia variedad de registros y formas textuales, dentro de las cuales las más reconocidas son la reseña, el ensayo y, más recientemente, el artículo académico. Esto ha hecho que formas como la nota, la glosa y el comentario, que han sido "personales" o "privadas", pues parecen hacer parte del resorte íntimo del lector, no hayan recibido mucha atención y que prácticas como la del diario de lectura, cultivada por Volkening, aún carezcan de estudios detallados. Si bien el cada vez más creciente interés en Nicolás Gómez Dávila ha atraído la atención sobre formas como el escolio y el aforismo, esta exploración se ha quedado en lo filosófico o en lo literario. Y las posibilidades que las formas breves ofrecen dentro de la crítica, la lectura y los estudios de recepción carecen de análisis importantes.

Mientras la expresión "formas argumentativas breves" caracteriza bien a modalidades de escritura como la máxima, el escolio o el epigrama, quizás una expresión como "formas marginales", en su acepción de textos escritos como anotación al margen de -o subordinados a- otro escrito sea más abarcadora. El designador "marginalia", acuñado por el poeta Samuel Taylor Coleridge en el siglo XIX, ha hecho carrera con dos implicaciones: una restringida, en el sentido físico del término, esto es, anotaciones en las márgenes de un libro ya publicado, y otra, amplia, simbólica, de alcances genológicos ${ }^{1}$, que abarcaría todas las formas de anotación crítica y comentario.

De acuerdo con H. J. Jackson, las formas marginales reproducen una práctica que viene desde la Edad Media, caracterizada por obedecer a métodos "privados" de anotación y lectura (5), los cuales, en tiempos recientes, han adquirido una gran utilidad para los estudios de recepción (6). El interés por las formas marginales recaería, entonces, sobre este componente receptivo, un tipo de lectura profesional que debería considerarse en una doble dimensión: primero en la "interpretación" y segundo "en el progreso de la interpretación, en el lector individual y en la gran comunidad de los lectores a lo largo

\footnotetext{
El adjetivo genológico hace referencia al ámbito de estudios que se ocupa de los géneros literarios. En este ámbito, confluyen problemas sincrónicos y diacrónicos. El género literario comporta asuntos inmanentes, de orden formal y temático, y asuntos vinculados con la historia de la lectura, la institucionalización de las normas, el canon y el campo.
} 
del tiempo"2 (Jackson 15). Los géneros marginales "son receptivos"; son comentarios que "necesitan ser leídos como fueron escritos, en conjunción con un texto principal"3 (Jackson 16).

Coleridge, a quien como ya se dijo se atribuye la invención de los marginalia como género de la crítica y la literatura, importó el término del latín, acaso para dar más alcurnia a su trabajo como anotador (Jackson 8). Si bien en su origen parecen ser notas "desinteresadas" (Jackson 10), con autonomía plena, de lo cual da cuenta su uso como nombre elegido ex profeso para una forma de escritura, cabe la posibilidad de que tengan una función preparatoria, es decir, que antecedan a una textualidad más orgánica y exhaustiva, por ejemplo, un ensayo, un estudio o una monografía. Un detalle para no olvidar es el hecho de que la palabra importada por Coleridge es un sustantivo plural, derivado del singular neutro latino marginale.

Dado que las anotaciones pueden ser verbales o no verbales, Jackson usa el término "nota discursiva" (14) para referirse a los comentarios propiamente dichos. Debe aclararse que se trata de notas marginales "reales", es decir, inscripciones manuscritas sobre libros ya publicados. Mientras que, en nuestro caso, se trata de notas tomadas a mano, aparte, de un texto inédito, seleccionadas y trascritas para ser comentadas en cuadernos. De manera que, en el caso particular del Volkening que lee a Gómez Dávila, hay un principio de selección que antecede a la nota misma, como si se tratara de una antología. Este principio es el que, a su vez, se podría invocar para hacer una tipología de los comentarios críticos y el que marca, de alguna manera, la identificación de las actitudes hacia lo leído. Adicionalmente, habría que decir que, en el caso de Volkening, estudiamos la proyección simbólica del arte material de la anotación sobre la designación de la actividad crítica. Se trata, si se quiere, de la elección de un género a partir de las actividades materiales que definen la lectura.

Si bien el análisis de Jackson se centra en casos específicos de anotaciones sobre libros que están en diferentes bibliotecas y colecciones, y que los análisis de caso tienen en su propuesta un papel medular, sí podemos extractar de

$2 \quad$ Interpretation and in the progress of interpretation, both in the individual reader and in the great society of readers over time. (De aquí en adelante, las traducciones de Jackson son de los autores de este artículo).

Marginalia are responsive; they need to be read as they are written, in conjunction with a prior text. 
su obra una serie de conclusiones metodológicas y proyecciones útiles para entender la lectura que hace Volkening.

La primera de ellas tiene que ver con la importancia que tiene el uso del espacio a la hora de entender los procesos de la anotación, algo que en el caso de Volkening tiene una solución, inducida por el soporte sobre el que transcribió los escolios y consignó sus propias notas. En segundo lugar, está el alto grado de continuidad histórica que ha tenido en la cultura libresca occidental la práctica de hacer anotaciones al margen, lo que permite apoyar, desde una nueva perspectiva, la afiliación de Gómez Dávila con un tipo de actividad escasamente estudiada en relación con su trabajo. Resulta evidente que la textualidad implícita a la que remiten los escolios resulta análoga con la actividad de quien los anota y los comenta. El escolio a un texto implícito es, sobre todo, una actividad de escritura en los márgenes.

Por otro lado, Jackson insiste en la necesidad de considerar los motivos del anotador y las funciones que él prevé para sus notas, por ejemplo, su autonomía y su heteronomía, los dos polos con los que sería preciso cotejar cualquier ejercicio de anotación marginal. Por último, vale la pena indicar que para Jackson el estudio de los marginalia debería contribuir, principalmente, a los estudios de autor y a los estudios de caso, lo que ayudaría a dar mayor visibilidad a un tipo de práctica tenida por insignificante.

En este artículo, si bien elegimos un objeto bastante particular, cinco cuadernos marca Norma en los que un crítico comentó sus impresiones y pensamientos sobre una obra que iba a publicarse, suponemos que los hallazgos ayudarán, sobre todo, a dos cosas: 1) entender la recepción de Gómez Dávila en Colombia y 2) conocer algunos de los métodos y hábitos intelectuales de uno de los críticos literarios y traductores más activos durante las décadas del sesenta y el setenta.

Las entradas del diario de lectura de Volkening, además de sus particularidades materiales y de contenido, tienen un valor adicional, pues se trata de formas que imitan anotaciones marginales, de manera que el margen se convierte en algo decididamente simbólico. Por otro lado, la nota al margen, el comentario y la entrada de diario vienen a ser como la objetivación de la ética del lector, de su compromiso vital con la escritura y la mediación. Se trata, en últimas, de notas sobre notas, de textos parasitarios que pueden ser formas acabadas o que pueden ser gérmenes de postulaciones más largas y complejas, pero que no son marginalia en el sentido lato del término, toda vez que, como se dijo, la consignación de lo comentado aún no está establecida. Las notas al margen de Volkening sobre el texto de Gómez Dávila vienen a ser, de alguna manera, 
como una especie de repositorio. De su uso posterior en un texto más largo y exhaustivo, dependen la autonomía o heteronomía -el valor intrínseco, si se quiere- que puedan tener. Lo que resulta interesante en el caso de Volkening es que dio a la anotación un valor en sí mismo y que esta supervivencia es la que, por ejemplo, permite que esos comentarios sean estudiados hoy.

Ahora bien, debemos admitir que las notas a los escolios de Gómez Dávila siguen dos dinámicas que, en la literatura, tienen el lugar de prácticas que ofrecen dos orientaciones: 1) la crítica literaria "oficial", relacionada con el comentario público, y 2) el diario, que habita en la esfera de la intimidad. En el caso de los cuadernos de Volkening estamos ante una lectura crítica privada y personal, sin la dimensión pública que reconocemos en la crítica publicada en periódicos, revistas o espacios académicos. Un detalle que quizás vale la pena tener en cuenta es que Volkening soluciona esta antinomia redactando comentarios que parecen dirigidos al autor de la obra, pues en ellos utiliza la segunda persona y dialoga con él, al punto de que los cuadernos terminan con una carta de balance y, a la vez, de admiración.

Esta polaridad entre lo público y lo privado estatuye una oposición complementaria: la que se da entre inmediatez y consolidación, entre opinión y teoría. Las formas argumentativas marginales se caracterizan por postular un tipo de respuesta en la que prima la impresión, la respuesta inmediata, la anotación a calamo currente. Sin embargo, la tarea continuada de hacer anotaciones va consolidando un propósito de permanencia y sistematicidad que no se puede excluir de la consideración. A fuerza de acumular anotaciones va emergiendo una especie de teoría propia, un andamiaje para el concepto general de la obra leída. Los cuadernos de Volkening son el primer testimonio sistemático del análisis y la discusión de una obra que ya desde su versión preliminar, esto es, antes de la publicación en libro por parte del Instituto Colombiano de Cultura (1977), revelaba sus grandes dimensiones. Por eso, constituye un caso de interés para los estudios sobre la recepción de un autor y la actividad crítica de un momento crucial en el pensamiento literario colombiano.

\section{ERNESTO VOLKENING, UN CRÍTICO DE LOS MÁRGENES}

Es sabido que uno de los principales méritos de la obra crítica de Ernesto Volkening fue haber hecho una apuesta decidida por autores a los que podría considerarse emergentes, no necesariamente por su juventud, sino más bien 
por la novedad de sus propuestas o por su discreta aparición en el panorama editorial del momento. De esta manera, abordó no solo valores consolidados, sino también carreras iniciales, primicias y apuestas de jóvenes escritores, como García Márquez, Óscar Collazos y Helena Araújo. Participando de una discusión ya establecida entre la tradición y la innovación estética, entre el canon y las rupturas, sus contribuciones ayudaron a que estos autores tuvieran un lugar.

$\mathrm{Y}$ es precisamente en este contexto donde Volkening tiene un sitio especial junto a Hernando Téllez como uno de los primeros críticos que leyó con atención y rigor a Nicolás Gómez Dávila, sin importar que lo leído se limitara a unos cuantos anticipos en las revistas Mito y Eco, a los dos libros que modestamente se imprimieron de Gómez Dávila y a los mecanoescritos que constituyeron el objeto de atención principal de los cuadernos. Volkening, como lector de esta obra aún en gestación, aparece en un momento particular, pues es el que antecede a la publicación de los Escolios a un texto implícito, la obra que daría poco después el reconocimiento internacional a Gómez Dávila. En buena medida, a los ojos del Ernesto Volkening crítico y lector, la compilación de escolios que recibió era una obra "en proceso".

La primera implicación de este carácter "procesual" de la lectura es que, en sus cuadernos, Volkening se enfrenta a los textos con la intención del editor, es decir, con los ojos de quien tiene una mirada, no por admirativa menos perfectible, del texto. Esta visión editorial de la lectura debe entenderse en su dimensión práctica, pero, también, en un sentido "poético". Volkening fue editor $y$, acaso, aspiraba con sus comentarios a mostrarse como alguien facultado para una futura edición de la que consideraba una contribución sin par a la filosofía y a las letras nacionales. Pero también perfeccionó en sus cuadernos su arte de la anotación, que llega con las notas a los escolios a una especie de plenitud formal, de belleza expresiva aprendida en la misma perfección constructiva de los escolios. La compilación leída y anotada por Volkening, y que difiere de la que a la larga se publicó en 1977, era, sin lugar a dudas, una obra "en proceso", con la que, quizás, pensaba contribuir. Los mecanoescritos eran, de esta manera, una obra cooperativa, a la que se sentía convidado.

En tal contexto, la transcripción, que de seguro iba haciéndose de manera sucesiva con la toma de notas, con el "anotado al margen", era una primera manera de preservar, difundir y criticar la obra próxima a aparecer. Como sostiene Steiner, "por encima de todo, la transcripción comporta un compromiso absoluto con el texto, una reciprocidad dinámica entre el lector y el libro" (15). 
Las relaciones de Volkening con la forma marginal y con las estrategias verbales y tipográficas del diario de lectura no eran nuevas. La crítica y los testimonios biográficos confirman que anotar al margen y escribir comentarios en cuadernos escolares era una actividad que tenía bien implantada en su cultura de lector, una cultura que estaba ya bien desarrollada cuando llegó en 1934 a Bogotá, donde empezó a publicar ensayos y comentarios desde 1947. La alusión a las notas, a los cuadernos y al diario de lectura no parece ser un mero motivo o un símbolo, como se acostumbra en las poéticas de la lectura recurrentes en la ficción contemporánea. Se trata de una práctica confirmada por quienes lo conocieron y dieron fe de su aplicación a la tarea de anotar y consignar en el diario personal todo lo leído.

En varios de números de la revista $E c o$, muchas de sus contribuciones críticas tenían, desde el título, la afiliación con las artes de la nota marginal. Una afiliación que merece toda la atención, si se quiere entender el tipo de posición que, como crítico, Volkening quería agenciarse. Así, por ejemplo, hay algunos escritos cuyo título empieza precisamente con la expresión "Anotado al margen", como ocurre con el texto que dedica a Cien Años de Soledad (Anotado al margen 259-303) y con el mismo trabajo que Volkening le dedicó a Gómez Dávila en 1978 (Anotado al margen de El reaccionario 95-99). Sirvan como ejemplo, aun más contundente, los resultados que da un pequeño censo de los textos en Eco que muestran términos claramente relacionados con esta forma de leer y escribir lo leído: "Extramuros", "hallazgos", "lecturas", "reivindicación", "fragmento", "editorial”, "digresión", "reflexiones", "crónica", "ripios", "improvisaciones", "notas", "de mis cuadernos", “descripción”, "sondeo", "apología”, "herejías”.

En "Anotado al margen de El reaccionario de Nicolás Gómez Dávila", Volkening se aproxima a uno de los temas recurrentes de los escolios del autor bogotano: el reaccionario. El crítico, a partir de lo dicho por Gómez Dávila, contrapone el reaccionario al progresista y lo acerca al radical. Llama la atención que este artículo publicado en Eco en 1978 tiene un carácter fragmentario. En lugar de un ensayo compacto, se trata de una transcripción de las notas tomadas al margen.

Debe tenerse presente que revistas como Eco y Mito prohijaban el interés por las formas marginales de lectura, que, de manera regular, incluyeron colaboraciones y aun secciones permanentes en las que el diario de lectura y el anotado al margen se invocaban como motivo. Por ejemplo, "Marginalia" y "Márgenes", en el caso de Mito, pasaron a ser nombres habituales, usados por autores como Hernando Téllez y Rafael Gutiérrez Girardot para presentar 
sus notas o impresiones de lectura, mientras que autores como Jorge Gaitán Durán publicaron habitualmente secciones de su diario de lectura. Acaso esta elección se explique por el deseo de establecer una distinción entre la crítica literaria hecha por literatos y la crítica que ya se empezaba a realizar en el mundo universitario. Al oponerse al tratado y a la monografía, formas como la nota o el diario acentuaban el ser mismo de la literatura, declarando que la mejor manera de dar cuenta del fenómeno literario era literaturizando la misma respuesta crítica, en una suerte de obra "de creación” (Steiner 12).

Es en este contexto donde el cuaderno y la libreta aparecen como motivos de la escritura y tópico al cual recurrir para el diseño de una figura autoral fuerte. Una figura autoral que, como sabemos, intenta caracterizarse a través de la imagen del lector. Así, la costumbre de llevar un diario de lectura se puede asociar más fácilmente con un tipo de respuesta que no quiere ser profesoral o académica, sino, más bien, vital. Quien lleva un diario para anotar las impresiones de lo leído hace más personal su trato con los libros.

Ahora bien, cabría preguntarse por la razón que impulsó a Volkening y a otros críticos de la época a optar por una cristalización formal semejante. ¿Por qué se llega a escribir de esa manera sobre obras literarias? ¿Qué búsqueda estética hay en el hecho de componer un diario y comprometerse con sus condiciones estructurales, fundamentalmente con la entrada, que es su unidad constitutiva? ¿Acaso porque hay un tipo de relación con el tiempo? ¿Porque es la manera más expedita de unir la vida con la escritura, de decir que la vida es lo que ocurre en los intersticios -espaciales, temporales- de una lectura? ¿El diario es el doble del escritor? ¿El diario de lectura es el hermano menor del ensayo y las otras formas meditativas?

Como plantea Steiner, las "acotaciones son los primeros indicios de la respuesta del lector hacia el texto, del diálogo entre el libro y él mismo. Son los indicadores activos de la corriente discursiva interior - laudatoria, irónica, negativa, potenciadora- que acompaña al proceso de la lectura" (Steiner 12). Las notas marginales son un índice de compañía y colaboración, muestras insoslayables de una lectura que es activa, comprometida con una respuesta. "Leer bien es contestar al texto, ser equivalente al texto, «una equivalencia» que contiene los elementos cruciales de respuesta y de responsabilidad. Leer bien es participar en una reciprocidad responsable con el libro que se lee, es embarcarse en un intercambio total" (Steiner 12).

Si bien no hay respuestas definitivas a los interrogantes sugeridos por las notas de Volkening, pues probablemente se encuentran en la intimidad de cada lector, sí podemos aventurar aproximaciones parciales a partir de la 
teoría que ha intentado explicar el funcionamiento de las formas marginales de escritura, índice de la recepción de los textos y de las tecnologías de apropiación de la tradición. En lo que sigue, intentaremos mostrar, con el mismo diario de lectura que Volkening dedicó con fervor a la obra inédita de Nicolás Gómez Dávila, una posible explicación. A la larga, la crítica y la obra literaria comentada tienen atributos semejantes y, por tanto, la forma breve se ofrece a sí misma como la más facultada para penetrar en un universo que no por fragmentario es menos valioso y coherente. Con el mismo Steiner, podemos decir que el diario de lectura confirma un ideal de la lectura: "Leer bien es ser leídos por lo que leemos. Es ser equivalente al libro” (Steiner 12).

\section{"CINCO MODESTOS CUADERNOS": VOLKENING Y LA PRIMERA LECTURA DE ESCOLIOS A UN TEXTO IMPLÍCITO}

La idea de que los cuadernos de Volkening vienen a ser algo así como un margen extendido, que por virtud de la escritura se amplía hasta ser la página completa, se confirma al atender a las características de los mismos cuadernos. Como recuerda Jackson, "la costumbre y al parecer la necesidad física dictan las clases apropiadas de uso para las áreas separadas en el libro"5 (18-19). Esta separación se hace dramática en los cuadernos de Volkening, toda vez que el margen se potencia hasta ser una de las partes constitutivas del volumen.

Los cinco cuadernos - que según hoy sabemos hacen parte de la obra de Ernesto Volkening- están catalogados erróneamente como un manuscrito de Nicolás Gómez Dávila en la colección de libros raros y curiosos de la Biblioteca Luis Ángel Arango de Bogotá. La primera entrada, fechada el 24 de mayo de 1973, da cuenta de la recepción de manos del propio Gómez Dávila de los siete tomos mecanoescritos, la cual, al parecer, y a juzgar por la misma anotación, tuvo lugar el día anterior. Volkening anuncia el propósito de asumir una "labor de lector atento y discreto con un profundo respeto" y, simultáneamente, tomar apuntes con el fin de "llenar este cuaderno y tal vez otros" (Sin título 1, t.1).

\footnotetext{
El sistema que seguimos para citar los cuadernos inéditos de Volkening dentro de paréntesis es el siguiente: Autor, Sin título, página, tomo. En este caso, "tomo" hace referencia al cuaderno.

Custom and perhaps physical necessity dictate appropriate kinds of use for separate areas in the book.
} 
En los tradicionales cuadernos marca Norma de pasta rústica, comunes para la época, están registradas la selección de los escolios y sus glosas. La distribución espacial de las anotaciones se conserva en los cinco cuadernos: la página izquierda -verso- está dividida en dos columnas. En la primera, Volkening registra la fecha, una cifra en números arábigos que indica la página de la que extrajo el escolio y una más en números romanos, que daría cuenta, tras una numeración de los textos que hay en cada página, del escolio que está comentando. Dichos números están al frente de la transcripción de los escolios seleccionados, ubicados en la segunda columna.

La página derecha -recto- es la elegida para conservar las anotaciones, glosas, las entradas del lector-crítico. Una primera mirada revela en ello el gesto del diarista, un gesto que se puede caracterizar, respecto de sus funciones críticas, en primer lugar, por su constante autorreferencialidad $y$, por el otro, por la regularidad de las anotaciones, que dejan una huella permanente, extendida, del acto de lectura. No hay que esforzarse mucho para entender que el ejercicio mismo de selección de los escolios revela algunos rasgos distintivos de Volkening: su formación como abogado, con algo de filosofía y letras hispánicas, su preferencia por los escolios relacionados con la historiografía y la filosofía y su tendencia a penetrar críticamente los textos comentados a través del cotejo de sus ideas con los cuerpos doctrinales a los que se refieren. Precisamente, el acto mismo de anotar es uno de los temas recurrentes de este diario de lectura y, en esa medida, uno de los constantes asuntos de reflexión. Él mismo se pregunta:

¿Hasta dónde implica mi manera de glosar los "Escolios" una manera hasta subjetiva, incluso arbitraria, de apreciar la obra del autor en cuanto escojo un aforismo que visto de conjunto, quizás le parezca menos importante; y en cambio pase por alto otro tal vez mucho más esencial para su pensamiento? ¿En qué medida reflejó tal modo de proceder sólo mi propia situación del momento, mis predilecciones y aversiones, $\mathrm{o}$-peor todavía- las limitaciones de mi intelecto, impidiéndome la adopción de una actitud verdaderamente comprensiva? (Sin título 2, t.1).

Además de introducir el designador genérico "glosa" y, con este, darnos pistas sobre su conciencia de que al comentar está ampliando el sentido de los escolios, hay también una reflexión sobre el proceso de selección inherente a esta forma de leer, extraer y comentar. Proceso que el mismo Volkening, cree, se da por "afinidad selectiva" porque, según dice, solo puede 
ver la personalidad detrás de los escolios a través de su "propio medio vital y espiritual", es decir, desprovisto de una "objetividad químicamente pura" (Sin título 2, t.1). Con esto, el crítico renano parece estar haciendo eco a las preguntas que se planteó Roland Barthes en el contexto de la discusión entre la nueva y antigua crítica en 1966 y que se condensan en Crítica y verdad: "¿qué es la objetividad en materia de crítica literaria?” (...) “¿cuál es la cualidad de la obra que existe fuera de nosotros?" (Barthes 17).

Llama la atención que la última entrada del quinto cuaderno sea una epístola dirigida a Nicolás Gómez Dávila, plena de una especie de admiración trémula después de la lectura:

Admirado y querido don Nicolás:

Perdóneme la familiaridad del encabezamiento que no se debe, por cierto, a falta de respeto ni a palurdos arranques de camaradería, sino sencillamente al haberme sentido muy cerca de usted mientras lo acompañaba tan largo trecho a través de los siete tomos de sus Escolios. Ahora, cuando ya toca a su fin el hermoso viaje que me fue permitido hacer en su compañía, me pregunto, qué pueda decirle para traducir en términos sinceros, justos y adecuados mi íntima convicción de haber leído un opus magnum, una obra de la cual no sé qué admirar más [...] (Sin título 15, t.5).

De esta podríamos inferir que el encargo de la lectura tuvo algún fin práctico -editorial o de otro tipo-y que estas impresiones fueron leídas alguna vez por Gómez Dávila. Pero también podríamos ratificar, con el rasgo comunicativo del género epistolar, la noción de interlocución propia de la lectura y, desde luego, de los géneros marginales.

En algunas notas hallamos una suerte de intención comunicativa, de respuesta a los postulados de Nicolás Gómez Dávila en una conversación mantenida en el tiempo que da la impresión de haber empezado mucho antes, pero que encuentra en las páginas de los cuadernos un espacio de realización que aspira a la perduración:

Digresión: Concibo mis apuntes a modo de diálogo amigable con el autor de un diálogo en el cual tácitamente presupongo la presencia de un tercero: el asno que escucha. Por esto soy a veces mucho más explícito de lo que fuera necesario tratándose de un interlocutor de la talla de NGD. Confío, pues, en que sabrá perdonar mis perogrulladas. (Sin título 19, t2). 
Algo interesante de esta nota es la observación sobre "la presencia de un tercero". Partimos de la intimidad del diario de lectura de Volkening, pero asistimos, en su propia propuesta, a un tránsito a la interlocución con el autor de los escolios e, incluso, a la consideración de otro lector. Siguiendo a Hans Rudolf Picard (1981), podríamos decir que dicha conciencia da cuenta de una intención comunicativa que marca un desprendimiento de lo íntimo para habitar la dimensión de lo público y que, en esa medida, ello podría ayudar a ratificar el estatuto literario de los cuadernos.

Los cuadernos son, pues, la continuación de una conversación entre dos intelectuales, lo que supone, necesariamente, el encuentro entre lecturas. El carácter dialógico de las notas se da como si, con cada escolio, Gómez Dávila propusiera un tema de conversación, una discusión y Volkening la continuara. Allí distinguimos fundamentalmente tres tendencias temáticas: la primera, relacionada con los temas recurrentes de la tradición literaria; la segunda, que dibuja una conversación sobre la sociedad, sus estructuras y el estado de las cosas y, la tercera, que se enfoca en lo concerniente a las ciencias humanas y sociales, su "deber ser" y los oficios que le competen.

En la primera línea temática observamos asuntos que apelan a la condición humana, como el amor, el miedo y la búsqueda de sentido. En este punto, Volkening conversa con escolios como "Mientras más opaco, más incoherente, más misterioso, sintamos al universo, más suavemente nos alberga" diciendo:

En estas palabras se expresa un "Weltgefühl"', un modo de sentir el mundo que, si no se detestara la manía anexionista de mis paisanos hasta en los dominios del espíritu, calificaría sin vacilar de"germano". En último análisis, se trata de algo extrañamente indefinible, ambiguo, suspendido entre los dos polos de la angustia cósmica y la sensación del "Geborgensein", de una afinidad entre el hombre y el universo, el microcosmos y el macrocosmos (Sin título 9, t.2).

Otro ejemplo lo hallamos en la respuesta que da al escolio "Todo lo amado es único. El amor es el órgano con que percibimos la inconfundible individualidad de los seres" en el que dice: "Si no estoy muy equivocado fue Scheler el primero en enseñarnos que el amor, en vez de «volvernos ciegos», como 
se cree, nos abre los ojos. Sin amor, sin una gran pasión subyacente no hay conocimiento que valga, ni idea que prospere" (Sin título 3, t.1).

Después, encontramos muchas referencias al hombre moderno y a los sistemas económicos y políticos imperantes. Gómez Dávila plantea, por ejemplo, que "la sociedad jerarquizada no es meramente la única donde el hombre puede ser libre, sino también la única donde le urge serlo". Volkening, en un evidente ejercicio de respuesta, dice:

Mi objeción: la única sociedad rigurosamente jerarquizada de nuestra época es la de la Unión Soviética (y de los Estados constituidos conforme a su modelo). Ergo. Estoy entusiastamente, rabiosamente de acuerdo: o restablecemos la primacía philosophiae o estamos perdidos. (Temo que ya sea tarde). (Sin títiulo 3, t.1).

Del predominio de este interés temático, se podría inferir que ambos autores tienen una marcada inclinación por lo constitutivo de las ciencias humanas y sociales. En esta conversación sobre los saberes y las prácticas, también se establecen relaciones y jerarquías entre la historiografía, la filosofía, el psicoanálisis, la sociología y la literatura. La mayoría de las veces, Volkening responde con construcciones concisas en las que no necesariamente amplía el sentido el texto, como cuando cita "todas las ciencias son meramente ciencias auxiliares del arte de la historia" y luego responde: "Los historiadores deberían ser los primeros en comprenderlo, y son los últimos en seguir la máxima" (Volkening, Sin título 7, t.1).

En otros casos, refuerza lo propuesto por el escoliasta, por ejemplo, cuando dice "a la inversa, se podría juzgar la filosofía por lo que, como la de Schopenhauer, tenga de buena literatura" ante el escolio "la literatura es la más sutil, y quizás la única exacta, de las filosofías" (Volkening, Sin título 30, t.1) y, en otros, da una respuesta incluso visceral. En alguna parte Volkening cita un escolio de Gómez Dávila que dice: "Los historiadores democráticos enseñan que el demócrata no mata sino porque sus víctimas lo obligaron a matarlas" y comenta: "No merecen llamarse historiadores. Son puercos" (Sin título 30, t.1).

Ahora bien, el ejercicio crítico que Volkening realiza en los cuadernos revela otras posibilidades analíticas. En este tipo de entradas, Volkening trasciende el diálogo con el autor de los escolios para generar un tipo de textualidad un poco más independiente del texto que comenta. Por ejemplo, cuando cita el escolio "la imaginación es una función esporádica de los sentidos que descubre un significado en la sensación misma y lo expresa simbólicamente. 
Las sirenas, por ejemplo, son la "sireneidad" de ciertos letargos meridianos y marinos", Volkening responde:

Aquí anda NGD muy cerca de la concepción de Friedrich W. Otto y del recién fallecido Karl Kerénji, las dos mentes más sutiles entre los mitólogos modernos. Pero lo que aun más me encanta: Descubrió con su don intuitivo una las más raras protoexperiencias del hombre, el encuentro con el "espectro de medio día", un gran fascinosum (Sin título 4, t.1).

El autor establece constantes relaciones entre los escolios de Gómez Dávila y pensadores como Marx, Jünger, Schopenhauer, Jung. Sus notas ubican la obra del escoliasta en un lugar en el que convergen la filosofía y la literatura: la agudeza y grandeza de las ideas y la excepcionalidad de la forma. Por ejemplo, leemos:

Por el vigor, la absoluta probidad intelectual (en fin, la herencia escolástica) se distinguen los aforismos de NGD de los de Ernst Jünger. Ambos autores tienen esprit ${ }^{8}$ de sobra, pero el de Jünger es lo que en alemán se llama "unverbindlich": no se compromete. Rara (mais bien allemande9, tiras!) esa falta de "Zivilcourage" 10 , esos melindres de vieja solterona en un hombre que en la primera guerra mundial fue condenado con él "Pour le mérite" NGD rompe lanzas por causas perdidas (Volkening, Sin título 10, t1).

Más adelante corrige su afirmación cuando dice: "Volviendo a lo que dije antes respecto de NGD y Jünger: no hay comparación entre los dos. Para encontrar a uno que sea de la talla del autor de los Escolios sería necesario remontarse hasta Pascal" (Volkening, Sin título 11, t1). Comparaciones como esta son comunes en los cuadernos. Vale la pena destacar que, si bien la actitud de Volkening es fundamentalmente analítica, se advierten juicios de valor que es necesario considerar para entender la manera en que el crítico se aproxima a los escolios de Gómez Dávila. Hay que recordar que el Volkening

Espíritu.

9 Pero bien alemán.

10 Valor cívico.

11 La Pour le Mérite, conocida informalmente como el Max Azul o Blue Max, era la máxima condecoración militar concedida por Prusia y luego por Alemania durante la Primera Guerra Mundial. 
lector tiene el interés de captar la esencia, el ser del escoliasta, pero el crítico busca, con su "inteligencia que compara y ordena", distinguir una obra que, a su entender, no tiene precedentes. Ante escolios como "gran escritor es el que moja en tinta informal la pluma que arranca al remo de un arcángel", Volkening no puede decir más que "ni en Heine he encontrado nada tan endiabladamente bueno como esta frase suspendida entre dos abismos" (Sin título 10, t1). Otro comentario que evidencia este asunto es el que escribe tras leer "El ser rezuma por todos los poros del mundo", dice "No sé a quién admirar más en este aforismo: al filósofo o al artista que creó la imagen del mundo que rezuma ser por los poros" (Sin título 4, t1).

Por otro lado, siguiendo a David Jiménez Panesso, indicábamos que la crítica literaria en Colombia se caracterizó, en la época de Mito y Eco, por su interés en ampliar a las humanidades y las ciencias sociales los marcos de comprensión de la obra literaria. Desde luego, las consideraciones sobre la literatura, la creación y el campo literario puestas en el contexto de las innumerables discusiones que llevan estos dos autores en los cuadernos permiten captar este interés. Ante escolios como "La decadencia de una literatura empieza cuando los lectores no saben escribir", Volkening comenta: "Esa misma incapacidad de escribir de los lectores, o sea de la pura receptividad, conduce a graves trastornos del metabolismo mental, a una verdadera autointoxicación. Eficaz antídoto: los 'Escolios' de NGD” (Sin título10, t2).

Volkening también se atreve a considerar el estado del campo literario en Colombia. Sin duda, esto tiene que ver con que su labor de crítico de la cultura le permitía tener una valoración del contexto nacional y le exigía pronunciarse sobre asuntos contemporáneos, a la luz de las palabras de Gómez Dávila. Por ejemplo, cuando lee "la literatura tiene por finalidad destacar todo aquello que la literatura tenía por propósito omitir. El escritor actual preferencialmente dice lo que el escritor de ayer callaba, no por inexperiencia o por miedo, sino por desdén", comenta: "En efecto, los autores de nuestra literatura excrementicia y espermatozóica me recuerdan a papá Buendía en "Cien años de soledad" quien, habiendo fracasado en su alquímico propósito de transmutar mierda en oro, sí logró reducir oro a mierda" (Volkening, Sin título 12, t.3).

Ahora bien, vale la pena retomar las consideraciones de Volkening sobre la obra que tiene en sus manos para observar que, si bien algunos de los elementos críticos hacen parte del cuerpo general del texto en el que sigue una agenda escolio-comentario, hay otras anotaciones que están dedicadas a las reflexiones formales de la obra de Gómez Dávila y que Volkening plantea 
como una pausa: un texto que no responde a ningún escolio, sino que más bien se ocupa de la obra como totalidad.

En este tipo de notas, que tienen una distribución espacial distinta y que, a partir del tercer cuaderno él mismo llama "digresiones", hay una marcada autorreferencialidad. Volkening se refiere a su propio proceso de lectura y a la evolución de sus apreciaciones sobre los Escolios. Allí reflexiona sobre asuntos de género y discute, por ejemplo, si los escolios son o no aforismos:

Me pregunto por qué al comenzar mis apuntes les negué a los 'Escolios' de NGD el carácter de aforismos sólo para ir convenciéndome de que sí como tales se definen en la acepción precisa del término, en su forma clásica, la del laconismo llevado hasta el último extremo. La respuesta es fácil: Partí de una premisa correcta y llegué a una conclusión falsa. Ciertamente ha caído en desuso el aforismo, pero no por eso debemos pensar que el aforismo sea "género menor", cosa de gente que no sabe hacer nada mejor, padeciendo "fuga de ideas" salta de un objeto a otro, piensa con ligereza, desordenadamente, o no piensa del todo, y por no tener en el fondo nada que decir, lo dice aforísticamente. Sería como afirmar que el ensayo no es un arte porque los que hoy día se escriben son cada vez más malos. Sucede sencillamente que NGD, quien además de ser pensador vigoroso es un enamorado del buen decir, le ha restituido a un género despreciado (por los tontos graves en primer lugar) su dignidad y su antiguo brillo. ¿Y cómo se hace un buen aforismo? El aforismo no se hace: Minerva saltando armada de la cabeza de Júpiter (Volkening, Sin título 8, t.1).

Esta autorreferencialidad no es solo semiótica, o literaria, se consuma también como intromisión biográfica. El autor no solo se sirve de sus lecturas para glosar los escolios de Gómez Dávila, también hace eco de anécdotas de infancia, observaciones de la vida cotidiana, relaciones y experiencias recientes para comentar al autor bogotano. En esa medida, podríamos decir que, así como el mismo Volkening considera que el "texto implícito" al que hace referencia Gómez Dávila es su vida misma "su quintaescencia, el fruto de varios decenios de intensa actividad espiritual" (Sin título 1, t.1) las entradas del diario de lectura también contienen la esencia de la experiencia vital del lector-crítico. Esto se evidencia en notas como "Así me lo explicó, casi con las mismas palabras, el doctor Ochsner ("Assistent" de Scheler, luego de Heidegger, después sui iuris) con ocasión de un memorable paseo que hace más de treinta y nueve años dimos en pleno invierno, a orillas del Dreisam, 
cerca de Friburgo en Brisgovia. Hermoso ejemplo de la afinidad espiritual a través del espacio y el tiempo" (Volkening, Sin título 12, t.1).

Ese elemento nos permite apreciar al mismo Volkening, su pensamiento, su posición vital, pero, más importante aún, nos deja ver con detalle el proceso cognitivo - de lectura, interpretación, ampliación y reescritura- que aparece en su ejercicio crítico. Vemos, pues, la manera en que el autor renano se compromete con la comprensión de una de las obras más desafiantes de la literatura colombiana del siglo xx. De la misma manera, al actuar como los "terceros lectores", ubicamos a Volkening en una posición de mediador -de intercesor- en el que nos servimos de su enriquecida lectura para ir con algo de luz al encuentro de la obra compacta y concreta de Gómez Dávila.

\section{CONCLUSIONES}

1. Los géneros argumentativos breves ofrecen una posibilidad inmejorable para comprender por lo menos tres fenómenos: a) la manera en que unos escritores leen a otros, lo que constituye una atalaya privilegiada para calibrar la recepción crítica de una obra o un autor; b) el funcionamiento de formas como la nota, el comentario y la entrada de diario dentro del sistema de géneros, lo que define su recibo estético y su capacidad de responder creativamente a otra creación; c) la gestación de las ideas y conceptos críticos en los márgenes de lo leído, la manera en que la ocurrencia transcrita deja una huella antes de convertirse en ensayo, en crítica, en teoría.

2. Estos tres asuntos plantean derroteros para la investigación sobre obras análogas a los diarios de lectura de Ernesto Volkening y se podrían formular en interrogantes como los siguientes: a) ¿Qué posición estética define el optar por formas menores de la "escritura" crítica? ¿Qué movimientos de la interpretación y qué tipo de gestión de una posición dentro del pacto valorativo se da cuando un autor opta por formas "privadas" y fragmentarias de la crítica? b) ¿Qué aspectos formales -desde los espaciales y tipográficos, hasta los netamente composicionales y retóricos- se vuelven relevantes a la hora de entender las notas al margen, cultivadas y guardadas por los escritores en sus archivos? ¿Los marginalia son géneros no ficcionales? ¿Los factores de estructuración artística del discurso son relevantes en ellos? 
c) ¿Qué pueden enseñarnos las notas y comentarios sobre la trayectoria de las ideas, sobre los procesos hermenéuticos y la manera en que la ocurrencia transita hasta convertirse en un comentario público? ¿De qué manera puede entenderse la comunicación entre escritores a propósito de manuscritos y obras en gestación? ¿Es el editor un tipo de lector que merece una consideración diferente? ¿Una lectura puede cambiar la fijación de una escritura?

3. Los diarios de lectura de los Escolios a un texto implícito llevados por Ernesto Volkening en 1973 llevan a considerar la necesidad de estudiar a autores que optaron por el comentario, la nota, y sobre todo el diario, como formas alternas al ensayo, el tratado, la reseña y el artículo. Los cinco cuadernos de Volkening contienen uno de los ejercicios de lectura más significativos de la crítica colombiana, un ejercicio que, no por haberse realizado de "manera privada", resulta menos ilustrativo de uno de los momentos más representativos de producción de formas como el fragmento, la nota, el escolio y la máxima. La futura edición de los cuadernos de Volkening permitirá, en su momento, dar a la investigación literaria una nueva fuente para comprender las ideas estéticas y los procesos de edición y circulación de escritos crecidos en la periferia de los géneros más reconocidos de la literatura. La importancia de estos apuntes coincide, acaso, con las mismas palabras de George Steiner: "El intelectual es, sencillamente, un ser humano que cuando lee un libro tiene un lápiz en la mano" (Steiner 15).

\section{BIBLIOGRAFÍA}

Textos de ERnesto Volkening

Volkening, Ernesto. Sin título. Manuscrito no publicado (5 cuadernos). Reposa en la Biblioteca Luis Ángel Arango: Colección de libros raros y curiosos, 1973.

Ensayos I. Destellos criollos. Bogotá: Instituto Colombiano de Cultura, Colección Autores Nacionales, 1975.

Ensayos II. Atardecer europeo. Bogotá: Instituto Colombiano de Cultura, Colección Autores Nacionales, 1976.

“Anotado al margen de El reaccionario de Nicolás Gómez Dávila”. Eco. Revista de la Cultura de Occidente 34/0205 (1978): 95-99 
"Anotado al margen de Cien Años de Soledad de Gabriel García Márquez". Eco. Revista de la Cultura de Occidente 15/087 (1967): 259-303.

\section{Otros TEXTOS CITADOS}

Barthes, Roland. Crítica y verdad. Trad. José Bianco. Buenos Aires: Siglo XXI, 1972.

Cobo-Borda, Juan Gustavo. "Epílogo. Del anacronismo considerado como una de las bellas artes”. Volkening, Ernesto. Ensayos I. Destellos criollos. Bogotá: Instituto Colombiano de Cultura, Colección Autores Nacionales, 1975. 323-326.

Gómez Dávila, Nicolás. Escolios a un texto implícito. Obra completa. Bogotá: Villegas Editores, 6 volúmenes, 2005.

Jackson, H. J. Marginalia. Readers writing in books. New Haven/London: Yale University Press, 2001.

Jiménez Panesso, David. Historia de la crítica literaria en Colombia. Bogotá: Centro Editorial Universidad Nacional de Colombia, 1992.

Picard, Hans Rudolf. "El diario como género entre lo íntimo y lo público". Anuario de la Sociedad Española de Literatura General y Comparada 4 (1981): 115-122.

Steiner, George. "El lector infrecuente". Leer y releer. Revista del Sistema de Bibliotecas Universidad de Antioquia 35 (2004).

Torres Duque, Óscar. El mausoleo iluminado. Antología del ensayo en Colombia. Bogotá: Biblioteca Presidencia de la República, 1997. 